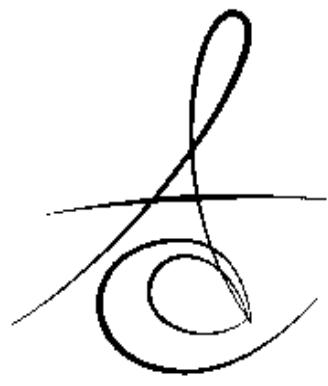

\section{DİŞ HEKİMLİĞİ PRATİĞİNDE ZİRKONYUM ve UYGULAMALARINA PANORAMİK BAKIŞ}

\section{A PANORAMIC VIEW OF ZIRCONIUM AND APPLICATIONS IN DENTAL PRACTICE}

\author{
Yrd. Doç. Dr. M. Barış GÜNCÜ* \\ Prof. Dr. R. Şenay CANAY*
}

Makale Kodu/Article code: 2635

Makale Gönderilme tarihi: 22.02.2016

Kabul Tarihi: 23.03.2016

\section{ÖZET}

Restoratif diş hekimliğinde materyal ve teknolojideki gelişmeler, biyomekanik özelliklerin yanı sıra estetik beklentileri de arttırmaktadır. Zirkonyum oksit seramikler; yüksek esneme direnci, gerilme ve baskı dayanımı, biyo-uyumluluğu ve estetiği ile restoratif diş hekimliğinde geniş kullanım alanı bulmuştur. Zirkonyum oksit seramikler, sabit bölümlü protezlerde alt yapı materyali olarak, kanal içi post ve kor uygulamalarında, inley ve onley restorasyonlarda, implant gövdesi ve dayanak üretiminde kullanılmaktadır. Bu derlemede, zirkonyumun diş hekimliğinde kullanım alanlarıyla ilgili güncel yaklaşımlar anlatılmıştır.

Anahtar Kelimeler: zirkonyum, zirkonyum yapısı, zirkonyum uygulama alanları

\section{ABSTRACT}

The developments of technology and material in the restorative dentistry, besides its biomechanical properties, increase the esthetical expectations. Zirconium oxide ceramics have found wide area of usage in restorative dentistry and high flexural strength, tensile, compression strength, biocompatibility and bioesthetics. While they have been also used as framework and endodontic post material, inlay and onlay restoration and implant abutments as well, they have been started to use in producing implant recently. In this review, current approaches related to the area of usage of zirconium in dentistry are being explained.

Keywords: zirconium, structure of zirconium, application of zirconium

\section{Zirkonyumun Yapısı ve Tarihçesi}

Zirkon adı farsça zar (altın) ve gun (renk) kelimelerinden türemiştir. Zirkonyum 1789 yılında Alman kimyacı Martin Heinrich Klaproth tarafından bazı değerli taşlar ısıtılarak elde edilmiştir. ${ }^{1}$ Zirkonyum atom numarası 40, atom ağırlığı 91.22, sembolü Zr olan metalik bir elementtir. Kimyasal olarak Hafniyum'a benzerliğinden dolayı saf zirkonyumu elde etmek oldukça zordur ve metalik zirkonyum kimyasal özelliğinden dolayı oldukça aktiftir. Özelliklerini fark edilir derecede değiştiren $\mathrm{N}, \mathrm{O}, \mathrm{H}$ ve diğer elementler ile çok kolay reaksiyona girer. ${ }^{2} \mathrm{Bu}$ nedenle, doğada hiçbir zaman serbest metal olarak tek başına bulunamaz. Hekzagonal kristal formunda bir yapı gösterir. Sıcaklığa ve korozyona karşı oldukça dirençlidir ve birçok farklı bileşik halinde bulunabilir. Bunların en önemlisi zirkonyum oksit $\left(\mathrm{ZrO}_{2}\right)$ bileşiğidir.

\section{Zirkonyumun Faz Değişimleri}

Zirkonyum oksit, zirkonyumun kristal yapıya sahip beyaz oksit halidir. Oldukça küçük çaplı taneciklerden oluşan bir materyaldir. Zirkonyum kristalleri üç farklı şekilde; Monoklinik (M), Tetragonal $(T)$ ve Kübik (C ) fazlar olmak üzere organize olabilirler. Zirkonyumun ergime derecesi $2680^{\circ}$ dir ve bu sıcaklığa kadar kübik fazdadır. Bu derecenin altına düşülürse kübik fazdan tetragonal faza geçiş gösterir. Tetragonal faz $2370^{\circ}$ 'ye kadar stabildir. $2370^{\circ}$ 'nin de altına inildiğinde tetragonal yapı tetragonamonoklinik faza dönüşür ve bu faz geçişi $1170^{\circ}$ 'nin altında gerçekleşir. Tetragonal fazdan monoklinik faza geçerken, kristallerin hacmi (\%4-\%5) artar, ki bu durum mikroçatlak veya makroçatlakların görünümü ve mekanik özelliklerinin kaybına neden olur., 3 Monoklinik faz oda sıcaklığında kırılgandır. Bu nedenle teknik uygulamalarda 
tetragonal fazdan monoklinik faza geçişi önlemek için bileşiğin stabilizasyonu gerekir. ${ }^{5}$ Yitriyum $\left(\mathrm{Y}_{2} \mathrm{O}_{3}\right)$, zirkonyumun $\left(\mathrm{ZrO}_{2}\right)$ tetragonal fazının sürekliliği için genel bir dengeleyici olarak kullanilır. Yitriyumla stabilize tetragonal zirkonyum polikristallerinin (Y-TZP) olağanüstü fiziksel ve mekanik özellikler sergilediği, yüksek esneme kuvveti, kırıma dayanımı, sertlik, asidik ve bazik ortam şartlarında aşınma ve korozyon direnci, translusensi, renk stabilitesi ve yüksek biyouyumluluğa sahip olduğu gösterilmiştir. ${ }^{6,7}$

Diş Hekimliğinde Zirkonyumun Üretim Şekilleri

Dişhekimliğinde zirkonyumun üretimi tam sinterize, yarı sinterize ya da green stage hazır bloklardan kazıma (frezeleme) yöntemi ile yapılır. Zirkonyum bloklar aynı kimyasal kompozisyona sahip olmalarına rağmen farklı bükülme dirençleri gösterebilirler. ${ }^{8} \mathrm{Bu}$ durum bloğun elde ediliş yönteminden kaynaklanır. Dişhekimliğinde kullanılan zirkonyum alt yapı materyalinin fiziksel özelliklerini ise sinterleme süreci ayrıca etkiler. ${ }^{9}$ Sinterleme; yüksek sıcaklıklarda partiküllerin birbirine bağlanmasını sağlayan ve gözenekli yapıdaki kütlenin yüzey alanının küçültülmesi, partikül temas noktalarının büyümesi buna bağlı olarak gözenek şeklinin ve hacminin küçülmesine neden olan Isıl işlem olarak tanımlanabilir. Zirkonyumun sinterlenmesi için bilinen en yaygın metod $1,350^{\circ}-1,600^{\circ} \mathrm{C}$ arasındaki sıcaklıklarda 2-4 saat konvansiyonel firında tutulmasıdır. Fırının bu sıcaklığa erişip daha sonra soğuması için gereken toplam süre ise ortalama 10-12 saattir. $\mathrm{Bu}$ yönteme alternatif olarak mikrodalga ile sinterleme ${ }^{10}$, spark plazma ile sinterleme ${ }^{11}$ ve vakum fırınlarının kullanımı gibi birçok metod tanıtılmıştır. Final sin- terizasyon sıcaklığı veya ısıtma metodu gibi sinteri- zasyon koşullarındaki çeşitlilik de, materyalin fiziksel veya mekanik özelliklerini etkileyebilir. ${ }^{12,13}$ Final sıcaklığı ve bu sıcaklıkta geçen süre; translusensiyi, yoğunluğu, pörözite ve zirkonyumun gren boyutunu direkt etkileyen belirleyici faktörlerdir. ${ }^{14}$ Tam sinterlenmiş zirkonya bloklar ise, istenilen final boyutunda frezelenebilir ve başka ısıl işlem uygulaması gerektirmez. Gözenekler arası fraksiyon hacminin daha düşük olması nedeniyle, yüksek kırılma dayanımına sahiptir ve hidrotermal yaşlanmaya dirençlidir. ${ }^{15}$ Bunun yanı sıra, tam sinterlenmiş blokların frezelemesi zor, pahalı ve daha uzun zaman alan bir uygulamadır. Frezeleme ucunun hızlı aşınması ve kazıyıcı frezin sürekli yenilenme intiyacı bu sistemin uygulanabilirliğini azaltmıştır. Parsiyel sinterize bloklar kolay şekillendirilmesine rağmen maksimum dayanıklılı̆a ulaşmaları için frezelemeden sonra sinterlenmelidir. Sinterlemeden sonra tam yoğunluğa ulaşır ve lineer büzülmenin yaklaşık \%25'i sinterizasyon sürecinde meydana gelir. ${ }^{16}$ Günümüzde, daha kolay frezeleme, kısa uygulama zamanı ve yüksek verimliliklerinden dolayı genellikle parsiyel sinterize bloklar kullanılır.

\section{Zirkonyumun Diş Hekimliğinde Kullanım}

\section{Alanları}

\section{Sabit bölümlü protezler}

Estetik ve biyouyumluluk gibi özelliklerinden dolayı zirkonyum, sabit bölümlü protezlerde sıklıkla tercih edilmektedir. Ancak, zirkonyum alt yapı materyali olarak kullanıldığında göreceli olarak yüksek opasite gösterir ${ }^{17}$ ve restorasyonun doğal dişlerin optik özelliklerini taklit edebilmesi için zirkonyum altyapı veneer porselenle kaplanır. ${ }^{3,18}$ Bununla birlikte veneer porselen ile kaplama, zirkonyum altyapıyı hidrotermal ayrışmadan korur. Zirkonyum ağız benzeri ıslak ortamlarda uzun süre sıvıya maruz kaldığında, zirkonyum kristallerinin tetragonal fazdan monoklinik faza dönüşmesine ve materyalin iç yapısında çatlaklar oluşmasına neden olabilir. ${ }^{19,20}$ Klinik çalışmalar bu durumun chippingé (Veneer porselenin zirkon alt yapıdan ayrılması) neden olabileceğini göstermiştir. ${ }^{21,22}$ Literatürde bu tür restorasyonlarda en sık rastlanan sorunun chipping olduğu rapor edilmiştir. ${ }^{23-25}$ Chipping insidansını etkileyen birçok faktör tanımlanmıştır;

1-Kor ve veneer materyalinin termal genleşme katsayısındaki farktan kaynaklanan rezidüel gerilim 2-Veneer porselen tarafından korun zayıf ıslanabilirliği 3-Porselen fırınlanmasından kaynaklanan basınç 4-Veneer ve korun ısınma ve soğuma protokolü 5-İşlem sürecinde doğal defektlerin oluşumu 6-Veneer seramik uygulama tekniği (tabakalama/ püskürtme)

7-Veneer seramiğin yetersiz kalınlığı

8-Okluzal travma

Sorunun çözümüne ilişkin olarak da farklı öneriler sunulmuştur. Fırınlama sonrası yavaş soğutma ${ }^{26}$, fırınlama sayısının azaltılması ${ }^{27}$, kron tasarımlarının modifikasyonu ve özellikle veneer porselen desteğinin geliştirilmesiyle daha dayanıklı restorasyonlar elde edilebilir. $^{28}$ 
Ayrıca bu tür problemlerin üstesinden gelebilmek için Dijital Veneering Sistem, (Lava $^{\mathrm{TM}}$ DVS,3M ESPE, Seefeld, Germany) yapım zamanını azaltmak ve daha estetik restorasyonlar üretmek için tanıtılmıştır. Bu sistem, CAD/CAM ile özel cam seramik bloklardan kazındıktan sonra füzyon tozlar kullanılarak, zirkonyum alt yapı ile porselen üst yapısını birleştirir. ${ }^{29}$ DVS tabanlı kronlar üç komponentten meydana gelir; zirkon koping, füzyon porselen ve işlenmiş cam seramik veneer. Bu sistem 8 kor rengi, 10 füzyon tozu, 4 cam seramikten oluşmaktadır. Her bir komponentte translusensinin farklı derecelerine ulaşılabilir. Cam seramik bloklarla mine renkleri, füzyon tozlarıyla dentin renkleri sağlanır. DVS ile estetik olarak doğal dişe daha yakın veneer seramikler üretilebilir.

Son yillarda veneer porselenle restore edilen zirkonyum altyapıda meydana gelen sorunları engellemek için monolitik zirkonyum sistemleri ortaya çıkmışıı. ${ }^{30}$ Herhangi bir veneer porselen uygulaması gerektirmeyen bu sistemlerde hata payı, üretim maliyeti ve zamanı göreceli olarak daha azdır. Opak ve monokromatik görünüm, polisaj ve glazeden sonra renk değişimi, karşıt doğal dentisyonda daha fazla aşınmaya yol açması ise dezavantajları olarak sıralanabilir. ${ }^{31} \mathrm{Bu}$ durum, estetiğin önemli olduğu olgularda ve aşııı buruksizm görülen hastalarda klinik kullanımını sınırlayabilir. Son yıllarda, lityum silikat seramikleri güçlendirmek amacıyla da zirkonyumdan faydalanılmaktadır. Dental marketlere yeni girmiş olan bu materyal hakkında sınırlı sayıda in-vitro çalışma ${ }^{32}$ bulunmakla birlikte klinik çalışma mevcut değildir.

\section{İnley ve Onley}

İnley ve onley restorasyonlar; konservatif yaklaşım ${ }^{33}$, optimum estetik ${ }^{34}$ ve daha iyi koronal SIZdırmazlık sağlamalarından dolayı restoratif dişhekimliğinin ayrılmaz parçası haline gelmiştir. Yaygın olarak kullanılan inley ve onley materyalleri; metal alaşımlar, kompozit rezinler, (hibrit veya fiberle güçlendirilmiş kompozitler)yüksek cam içerikli seramikler (lityumdisilikat, cam infiltre zirkonyum veya alüminyum oksit kristalleri) ve yüksek dayanıkı seramiklerdir(zirkonyum ve alüminyum oksit kristalleri ). ${ }^{35,36}$ Cam seramik materyaller; estetik, termal ekspansiyon katsayısı, sertlik, mineye benzer aşınma direnci ${ }^{37,38}$ ve adeziv simantasyon ${ }^{39,40}$ gibi özellikleri sebebi ile sıklıkla tercih edilir. Seramiklerin yüksek elastisite modülünden dolayı ${ }^{41,42}$ özellikle posteriorda fazla okluzal kuvvet alan bölgelerde, inley destekli restorasyonların en büyük problemi kırılma olasılığıdır. ${ }^{43}$ Diğer tam seramik materyallere kıyasla dayanıklığı 44 fazla olan zirkonyum bu amaçla son yıllarda tercih sebebi olmuştur. Labora- tuvar çalışmaları zirkonyumdan üretilen inley destekli sabit dental protezlerin yük taşıma kapasitelerinin lityum disilikatlardan daha yüksek olduğunu göstermiştir. ${ }^{45,46}$ Bununla birlikte, zirkonyum restorasyonlarda adeziv teknikler uygulandığında tek faz tetragonal kristal yapısından dolayı bağlantı sorunları görülür. ${ }^{47,48}$ Restorasyonların pürüzlendirilmesi için hidroflorik asit gibi ajanlar etkili olmazlar. Bu nedenle uzun dönem çalş̧malarda, desimantasyon, mikrosızıntı ve seramik veneer materyalinde mikro çatlak oluşumu rapor edilmiştir. ${ }^{49,50}$

\section{Zirkonyum Post}

Post ve kor materyali olarak zirkonyum Meyenberg ve arkadaşları tarafından tanıtımış ve ilk olarak 1993'te kullanılmaya başlanmıştır. ${ }^{51}$ Zirkonyum post, yüksek dayanıklıkk, eğilme direnci ve uygun optik özellikler gibi birçok avantaja sahiptir. Zirkonyum post prefabrike veya kişiye özel olarak hazırlanabilir. Prefabrike zirkonyum post uygulamasında, kor materyali olarak kompozit rezinler veya preslenmiş seramiklerle birlikte kullanılmaktadır. Ancak, prefabrike zirkonyum post uygulamasında en sık karşılaşlan sorun, kor ile postun birbirinden ayrılmasıdır. ${ }^{52-54}$ Bununla birlikte, zirkonyum postların elastisite modülü fiber postlardan çok daha yüksek olduğu için çiğneme kuvvetlerinin fazla olduğu posterior bölgede kulanımında dikkat edilmelidir. Özellikle parafonksiyonel aktiviteye sahip bireylerde, kök kııklarına neden olabileceğinden dolayı zirkonyum postların kullanımının uygun olmadığı rapor edilmiştir. ${ }^{55,56}$

Kişiye özel zirkonyum post-kor üretim tekniği ise ilk olarak Awad ve Marghalani ${ }^{57}$ ve Streacker ve Geissberger ${ }^{58}$ tarafından tanıtılmışıı. Prepare edilen kanal ve kalan diş dokusunun ölçüsü rezin patern ile dublike edilmiş, bu model taranmış ve post CAD/CAM ile Y-TZP bloklardan frezelenerek üretilmiştir. $\mathrm{Bu}$ teknikle daha yüksek dayanıklılı, kanala maksimum adaptasyon ve yeterli estetik sağlanmıştır. Bittner ve arkadaşlarının ${ }^{59}$ yaptığı bir çalışmaya göre prefabrike post-korların belirli yükler altındaki başarısızlık oranları kişiye özel post-korlar ile karşılaştıııldığında anlamlı derecede yüksek bulunmuştur. Zirkonyum post-korlar, özellikle anterior bölgede tam seramik restorasyonlar

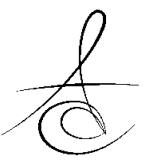


altında doğal diş görünümü ve estetiğin sağlanmasına olumlu etkide bulunurlar (Resim 1-3).

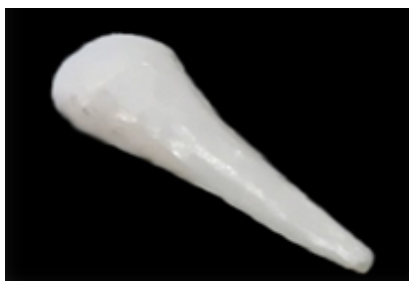

Resim 1. Kişiye özel hazırlanmış zirkonyum post- core

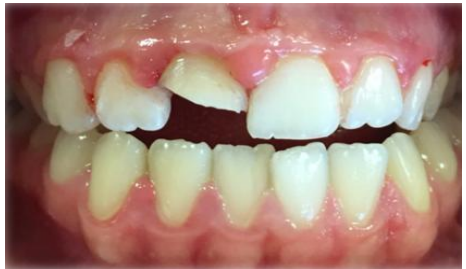

Resim 2. Tedavi öncesi ağıziçi görünüm

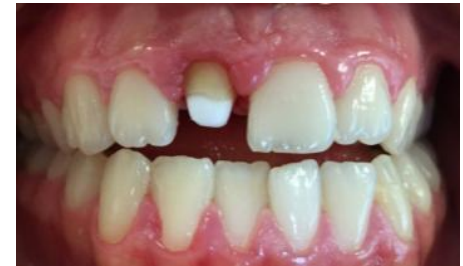

Resim 3. Zirkonyum post-core simante edildikten sonra ağıziçi görünüm

\section{Zirkonyum Abutment}

Altın standart olarak sunulan titanyum abutmentların implant çevresi mukozada gri renklenmeye neden olduğu çok sayıda klinik çalışmada rapor edilmiştir. ${ }^{60-62}$ Bu sorunu önlemek amacıyla son yıllarda zirkonyum abutmentlar (Resim 4), özellikle anterior bölgede doğal diş görünümü elde etmek için tam seramik restorasyonlarla birlikte sıklıkla tercih edilmektedir. ${ }^{63}$ Zirkonyum diğer tam seramik materyallerle (alüminyum oksit ve feldspatik porselenler v.b.) karşılaştırıldığında çok daha iyi mekanik özellikler göstermektedir. ${ }^{64}$ Bununla birlikte, uzun dönem klinik çalışmaları taklit eden in-vitro araştırmalarda zirkonyum içerisinde yaşlanmaya bağlı çatlaklar meydana gelebi leceği ve bunun da zirkonyum abutmentta uzun dönemde başarısızlığa neden olabileceği rapor edilmektedir. ${ }^{65,66}$ Bundan dolayı son yıllarda titanyum tabanlı (ti-base) zirkonyum abutmentlar daha çok tercih edilmeye başlanmıştır ${ }^{67}$ (Resim 5-6). Bu tür hibrid abutmentlar firma tarafindan üretilen titanyum taban üzerine orijinal yazılım kullanılarak bu parçanın dış yapısına uygun üretilen zirkon yapının rezin esaslı siman ile yapıştıııması ile elde edilir. Hibrid abutmentların stabilitesi üzerine yapılan çalışmalarda hibrid abutmentların daha iyi mekanik özellikler gösterdiği rapor edilmiştir. ${ }^{67}$ Hibrid abutmentlarda dikkat edilmesi gereken durum ise titanyum taban-zirkon bağlantsıdır. Zirkonyum seramik ve titanyum taban için çeşitli bağlanma metodları rapor edilmiştir. ${ }^{68}$ Titanyum taban ile üzerine üretilen CAD/CAM zirkonyum kopinglerin retansiyonu hakkında sınırlı sayıda çalışma mevcuttur. Siman türü, siman kalınlığı ve yüzey şartlandırma metodları titanyum taban üzerine yapıştırılan zirkonyum seramik copingin retansiyonunu önemli derecede etkiler. ${ }^{69} \mathrm{MDP}$ içeren rezin simanların veya rezin modifiye cam iyonomer simanların kullanımının retansiyon değerlerini arttırdığı gözlenmiştir. ${ }^{70}$ Sonuç olarak hem tek parça hem de hibrid yapıdaki zirkonyum abutmentların estetik bölgede kullanılması doğal diş görünümüne en yakın estetik sonucun sağlanması için her geçen gün yaygınlaşmaktadır.

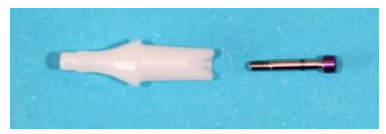

Resim 4. Zirkonyum abutment, abutment vidası

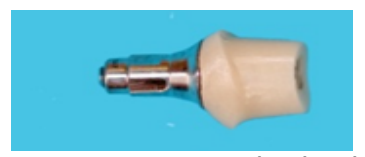

Resim5.Titanyum tabanlı zirkonyum abutment

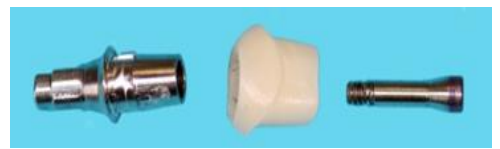

Resim 6. Titanyum taban, zirkonyum alt yapı, abutment vidası

\section{Zirkonyum İmplantlar}

Zirkonyumun, son yillarda implant gövde materyali olarak kullanımı gündeme gelmiştir. ${ }^{71}$ Implant gövde materyali olarak kullanılma nedenleri; biyouyumluluk, kimyasal ve boyutsal stabilite, yüksek bükülme kuvveti (900-1200MPa), yeterli sertlik (1200 Vickers), diş benzeri renk özellikleri, düşük termal iletkenlik, kolay işlenebilirlik, titanyumla kıyaslanabilir kemikle integrasyon, azalmış plak afinitesi ve düşük korozyon potansiyeli gibi özellikleri ile ön plana

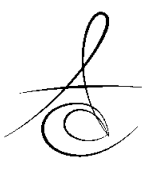


çıkmaktadır. ${ }^{72-77}$ Hücre kültürü çalışmalarında zirkonyuma karşı olumlu biyolojik reaksiyon gözlenmiş ${ }^{78}$ ve hayvan deneylerinde de zirkonyum implantların osseointegrasyonunun başarılı olduğu rapor edilmiştir. ${ }^{79}$ Kohal ve ark. ${ }^{79}$ aynı maymun modellerde zirkonyum implant yüklemesiyle, titanyumu karşılaştırmıştır. 14 aylık gözlem periyodunda implant kaybı bulunmamış ve herhangi bir mekanik problem rapor edilmemiştir. Histolojik incelemede, titanyum ve zirkonyum implantlar arasında kemik dokusunun cevabında herhangi bir fark görülmemiştir. İmplantın uzun dönem başarısı materyalin kemik integrasyonu başarısı ile doğrudan ilişkilidir. ${ }^{80}$ Bununla birlikte, implant materyalinde ve onu çevreleyen kemik dokularda oluşan stresler başarıyı etkileyen diğer önemli bir faktördür. Caglar ve ark. ${ }^{81}$ yaptıkları sonlu elemanlar stres analizi çalışmasında, tek parça titanyum implant, titanyum implant üzerine vidalanan zirkonyum abutment ve tek parça zirkonyum implantların kortikal kemik üzerinde oluşturduğu stresi değerlendirilmiştir ve tek parça zirkonyum implantların kortikal kemikte daha az stres oluşturduğunu rapor etmişlerdir. Zirkonyum implantların fiziksel özellikleri hakkındaki endişelerden dolayı, bu tür implantlar tek parça olarak üretilmiştir. Ancak tek parça implantlarda cerrahi sırasında implantın açısal olarak yanlış konumlandırımasına bağlı hataların protetik aşamada düzeltilemeyecek olması en büyük dezavantajıdır. ${ }^{82}$ İmplantın herhangi bir noktadan kırılması durumunda da, tamir edilmesi mümkün değildir ve kemik içerisinden çıkartılması zorunludur. ${ }^{83}$ Son yıllarda, iki parça zirkonyum implantlar üretilmeye başlanmış ve klinik kullanıma sunulmuştur. Bu konu ile ilgili çalışmaların çoğu olgu sunumu şeklindedir. ${ }^{84-86}$ Günümüzde henüz rutin muayenehane pratiğinde kullanılmasa da, ilerleyen yıllarda zirkonyum implantların özellikle ön bölge estetik olgularda uygulanması öngörülmektedir.

\section{SONUÇ}

Zirkonyum oksit seramiklerin dişhekimliği pratiğine girmesinden günümüze kadar giderek artan bir hızla kullanım alanları genişlemektedir. Yapılan in-vitro ve klinik çalışmalar da zirkonyum destekli materyallere hekimlerin ilgisini arttırmakta ve rutin uygulamalarda kullanımını cesaretlendirmektedir. İlerleyen yıllarda materyale özgü sınırlamaların ve endikasyonların daha net ortaya konması ile dişhekimliği pratiğinde öncelikli tercih sebebi olabilir.

\section{KAYNAKLAR}

1. Piconi C, Burger W, Richter HG, et al. Y-TZP ceramics for artificial joint replacements. Biomaterials 1998;19:1489-94

2. Elyutin V.P. "Ferroalaşımların İstihsali Elektrometalurji Kitabı, ITÜ Matbaası İstanbul Üniversitesi 17. 1968.p:104-75

3. Conrad HJ, Seong WJ, Pesun IJ. Current ceramic materials and systems with clinical recommendations:A Systematic Review 2007; 98: 389-404.

4. Deville S, Chevalier J, Gremillard L. Influence of surface finish and residual stresses on the ageing sensitivity of biomedical grade zirconia. Biomaterials 2006;27:2186-92.

5. Butler E.P. Transformation-toughened zirconia ceramics. J. Mater Sci Technol 1985;1:417-32.

6. Vagkopoulou T, Koutayas SO, Koidis P, Strub JR. Zirconia in dentistry: part 1 . Discovering the nature of an upcoming bioceramic. Eur J Esthet Dent 2009;4:130-51.

7. Karakoca S, Yılmaz H. Zirkonyum ve sabit protezlerde kullanımı. Atatürk Üniv Diş Hek Fak Derg 2006;36-44.

8. Uludamar A, Şeyda A, Özkan Y. Zirkonya esaslı tam seramik restorasyonlar. Atatürk Üniv Diş Hek Fak Derg 2012;132-41.

9. Denry I, Kelly JR. Emerging ceramic-based materials for dentistry. J Dent Res 2014; 93: 123542.

10. Almazdi AA, Khajah HM,.Monaco EA Jr, Kim $\mathrm{H}$. Applying microwave technology to sintering dental zirconia. The journal of prosthetic dentistry 2012; 108:304-9.

11. Tsukada G, Sueyoshi H, Kamibayashi H, Tokuda M , Torii M. Bending strength of zirconia/porcelain functionally graded materials prepared using spark plasma sintering. Journal of Dentistry 2014;42:1569-76.

12. Stawarczyk B, Ozcan M, Hallmann L, Ender A, Mehl $\mathrm{A}$, Hämmerlet $\mathrm{CH}$.The effect of zirconia sintering temperature on flexural strength, grain size, and contrast ratio. Clin Oral Investig 2013;17:269-74.

13. Karakoca $S$, Yilmaz $H$. Influence of surface treatments on surface roughness, phase transformation, and biaxial flexural strength of $\mathrm{Y}$ TZP ceramics. J Biomed Mater Res B Appl Biomater 2009; 91: 930-7. 
14. Ebeid K, Wille S, Hamdy A, Salah T, El-Etreby A, Kern $M$. Effect of changes in sintering parameters on monolithic translucent zirconia. Dent mater 2014;30:419-24.

15. Suttor D, Bunke K, Hoescheler S, Hauptmann $H$, Hertlein G. LAVA- the system for all-ceramic ZrO2 crown and bridge frameworks. Int J Comput Dent 2001;4:195-206.

16. Denry I, Kelly JR. State of the art of zirconia for dental applications. Dent Mater 2008;3:299-307.

17. Zhang Y. Making yttria-stabilized tetragonal zirconia translucent. Dent Mater 2014;30:1195203.

18. Piconi C, Maccauro G. Zirconia as a ceramic biomaterial: A review. Biomaterials 1999;20:1-25.

19. Chevalier J, Loh J, Gremillard L, Meille S, Adolfson E. Low-temperature degradation in zirconia with a porous surface. Acta Biomaterialia 2011;7:298693.

20. Kim JW, Covel NS, Guess PC, Rekow ED, Zhang Y. Concerns of Hydrothermal Degradation in CAD/CAM Zirconia. J Dent Res 2010;89:91-5.

21. Sailer I,Gottnerb J, Kanelb S, Hammerle CH. Randomized controlled clinical trial of zirconiaceramic and metal-ceramic posterior fixed dental prostheses :A 3-year follow-up. Int J Prosthodont 2009;22:553-60.

22. Christensen RP, Ploeger BJ. A clinical comparison of zirconia, metal and alumina fixed-prosthesis frameworks veneered with layered or pressed ceramic: A three-year report. J Am Dent Assoc 2010;141:1317-29.

23. Sax C, Hämmerle CH, Sailer I. 10-Year clinical outcomes of fixed dental prostheses with zirconia frameworks Int J Comput Dent 2011;14:183-202

24. Beuer F, Stimmelmayr M, Gernet W, Edelhoff D, Güh JF, Naumann M. Prospective study of zirconiabased restorations: 3 year clinical results Quintessence Int 2010;41:631-37.

25. Agustín-Panadero R, Román-Rodríguez JL, Ferreiroa A, Solá-Ruíz MF, Fons-Font A. Zirconia in fixed prosthesis. A literature review J Clin Exp Dent 2014;6:66-73.

26. Komine F, Saito A, Kobayashi K, Koizuka M, Koizumi $H$, Matsumura $H$. Effect of cooling rate on shear bond strength of veneering porcelain to a zirconia ceramic material. J Oral Sci 2010;52:64752.

27. De Jager $N$, Pallav $P$, Feilzer AJ. The influence of design parameters on the FEA-determined stres distribution in CAD-CAM produced all-ceramic dental crowns. Dent Mater 2005;21:242-51.

28. Silva NR, Bonfante EA, Zavanelli RA, Thompson VP, Ferencz JL, Coelho PG. Reliability of metalloceramic and zirconia-based ceramic crowns. J Dent Res 2010;89:1051-6.

29. Kim KY, Kwon TK, Kang TJ, Yang JH, Lee SJ, Yeo IS. Digital veneering system enhances microtensile bond at zirconia core-veneer interface. Dent Mater 2014;33:792-8.

30. Zhang Y, Lee JJ, Srikanth R, Lawn BR. "Edge chipping and flexural resistance of monolithic ceramics," Dent Mater 2013;29:1201-08.

31. Griffin JD Jr. Combining monolithic zirconia crowns, digital impressioning, and regenerative cement for a predictable restorative alternative to PFM. Compend Contin Educ Dent 2013; 34: 21222.

32. Sato TP, Anami LC, Melo RM, Valandro LF, Bottino MA. Effects of surface treatments on the bond strength between resin cement and a new zirconia-reinforced lithium silicate ceramic. Oper Dent 2016;41:284-92.

33. Guess PC, Strub JR, Steinhart N, Wolkewitz M, Stappert CF. All-ceramic partial coverage restorations-midterm results of a 5-year prospective clinical splitmouth study. J Dent 2009;37:627-37.

34. Heymann HO, Bayne SC, Sturdevant JR, Wilder AD Jr, Roberson TM. The clinical performance of CADCAM-generated ceramic inlays: a four-year study. J Am Dent Assoc 1996;127:1171-81.

35. Molin $M$, Karlsson $S$. The fit of gold inlays and three ceramic inlay systems. A clinical and in vitro study. Acta odontol Scand 1993;51:201-6.

36. Edelhoff D, Spiekermann H, Yildirim M. "Metal-free inlay-retained fixed partial dentures," Quintessence Int 2001;32:269-81.

37. O'Brien WJ: Dental Materials and Their Selection. 3 ed. Quintessence 2002.p.210-25.

38. Stappert CF, Att W, Gerds T, Strub JR. Fracture resistance of different partial-coverage ceramic molar restorations An in vitro investigation. J Am Dent Assoc 2006;137:514-22.

39. Barghi N, Fisher DE, Vatani L. Effects of porcelain leucite content, types of etchants, and etching time on porcelain-composite bond. J Esthet Restor Dent 2006;18:47-52.

40. Kramer N, Taschner M, Lohbauer U, Petschelt A, Frankenberger R. Totally bonded ceramic inlays

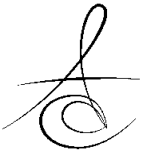


and onlays after eight years. Adhes Dent 2008;10:307-14.

41. Goodacre CJ, Bernal G, Rungcharassaeng K, Kan JY. Clinical complications in fixed prosthodontics. J Prosthet Dent 2003;90:31-41.

42. Raigrodski AJ, Chiche GJ, Potiket N, Hochstedler JL, Mohamed SE, Billiot S, Mercante DE. The efficacy of posterior three-unit zirconium-oxidebased ceramic fixed partial dental prostheses: a prospective clinical pilot study. J Prosthet Dent 2006;96:237-44.

43. Mynampati P, Babu MR, Saraswathi DD, Kumar JR, Gudugunta L, Gaddam D. Comparison of structure fracture resistance and failure pattern of endodontically treated premolars with diffrent esthetic onlay systems: An in vitro study. J Conserv Dent 2015;18:140-3.

44. Denry I, Kelly JR. State of the art of zirconia for dental applications. Dent Mater 2008;24:299-307.

45. Wolfart S, Ludwig K, Uphaus A, Kern M. Fracture strength of all-ceramic posterior inlay-retained fixed partial dentures. Dent Mater 2007;23:151320.

46. Puschmann D, Wolfart S, Ludwig K, Kern M. Loadbearing capacity of all-ceramic posterior inlayretained fixed dental prostheses. Eur J Oral Sci 2009; 117:312-8.

47. Thompson JY, Stoner BR, Piascik JR, Smith R. Adhesion/ cementation to zirconia and other nonsilicate ceramics: where are we now? Dent Mater 2011; 27: 71-82.

48. Jevnikar P, Krnel K, Kocjan A, Funduk N, Kosmac $T$. The effect of nano-structured alumina coating on resin-bond strength to zirconia ceramics. Dent Mater 2010; 26:688-96.

49. Roediger M, Gersdorff N, Huels A, Rinke S. Prospective evaluation of zirconia posterior fixed partial dentures: four-year clinical results. Int $\mathrm{J}$ Prosthodont $2010 ; 23: 141-8$.

50. Re D, Augusti D, Augusti G, Giovannetti A, "Early bond strength to low-pressure sandblasted zirconia: evaluation of a self-adhesive cement," Eur J Esthet Dent 2012;7:164-75.

51. Meyenberg $\mathrm{KH}$, Lüthy $\mathrm{H}$, Schärer P. Zirconia posts: a new all-ceramic concept for nonvital abutment teeth. J Esthet Dent 1995;7:73-80.

52. Al-Thobity AM. Clinical Outcomes of Zirconium Oxide Posts:Up-to -Data Systematic Review. Compend Contin Educ Dent 2016 ;37:17-20.
53. Zhou TF, Zhang XH, Wang XZ. Three-dimensional finite element analysis of one- piece computer aided design and computer aided manufacture involved zirconia post and core. Beijing Da Xue Xue Bao 2015;47:78-84.

54. Xible AA, de Jesus Tavarez RR, de Araujo Cdos $\mathrm{R}$, Bonachela WC. Effect of Silica coating and silanization on flexural and composite-resin bond strengths of zirconia posts: An in vitro study. J Prosthet Dent 2006; 95:224-9.

55. Ozkurt Z, Işeri U, Kazazoğlu E. Zirconia seramic post systems:a literature review and a case report. Dent Mater J 2010;29:233-45.

56. Fernandes AS, Dessai GS. Factors affecting the fracture resistance of post-core reconstructed teeth: a review. Int J Prosthodont 2001;14:355-63.

57. Awad MA, Marghalani TY. Fabrication of a custommade ceramic post and core using CADCAM technology. J Prosthet Dent 2007;98:161-2.

58. Streacker $A B$, Geissberger $M$. The milled ceramic post and core: a functional and esthetic alternative. J Prosthet Dent 2007;98:486-7.

59. Bittner N, Hill T, Randi A. Evaluation of a one-piece milled zirconia post and core with different postand core systems: An in vitro study.J Prosthet Dent 2010;103:369-79.

60. Bressan E, Paniz G, Lops D, Corazza B, Romeo E, Favero $G$. Influence of abutment material on the gingival color of implant supported all-ceramic restorations: a prospective multicenter study. Clin Oral Implant Res 2011;22:631-7.

61. Jung RE, Sailer I, Hämmerle CH, Attin T, Schmidlin P. In vitro color change of soft tissues caused by restorative materials. Int J Periodontics Restorative Dent 2007;27:251-7.

62. Sailer I, Zembic A, Jung RE, Hämmerle $\mathrm{CH}$, Mattiola A. Single-tooth implant reconstructions: esthetic factors influencing the decision between titanium and zirconia abutments in anterior regions. Eur J Esthet Dent 2007; 2: 296-310.

63. Glauser R, Sailer I, Wohlwend A, Studer S, Schibli $M$, Schärer $P$. Experimental zirconia abutments for implant-supported single-tooth restorations in esthetically demanding regions: 4-year results of a prospective clinical study. Int J Prosthodont 2004;17:285-90.

64. Tinschert J, Natt G, Mautsch W, Augthun M, Spiekermann $H$. Fracture resistance of lithium disilicate ,alumina and zirconia based three unit

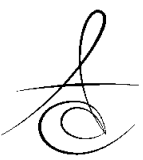


fixed partial dentures:a laboratory study. Int J Prosthodont 2001;14:231-8.

65. Chevalier J, Olagnon C, Fantozzi G, Cales B. Crack propagation behavior of Y-TZP ceramics. J Am Ceram Soc 1995;78:1889-94.

66. Chevalier J, Olagnon C, Fantozzi G. Crack Propagation and fatigue in zirconia-based composites. 1999;30: 525-530.

67. Gehrke P, Johannson D, Fischer C, Stawarczky B, Beuer $F$. In vitro fatigue and fracture resistance of one- and two-piece CAD/CAM zirconia implant abutments. Int $\mathrm{J}$ Oral Maxillofac Implants 2015;30:546-54.

68. Gehrke P, Alius J, Fischer C, Erdelt KJ, Beuer F.Retentive strength of two -piece CAD/CAM zirconia implant abutments.Clin Implant Dent Relat Res 2014;16:920-5.

69. Ebert A, Hedderich J, Kern M. Retention of zirconia ceramic copings bonded to titanium abutments. Int J OralMaxillofac Implants 2007; 22:921-927.

70. Nejatidanesh F, Savabi O, Shahtoosi M. Retention of implant-supported zirconium oxide ceramic restorations using different luting agents. Clin Oral Implants Res 2013;24:20-4.

71. Aydin C, Yilmaz H, Ata SO. Single-tooth zirconia implant located in anterior maxilla. A clinical report. N Y State Dent J 2010;76:30-3.

72. Sennerby L, Dasmah A, Larsson B, Iverhed M. Bone tissue responses to surface-modified zirconia implants: A histomorphometric and removal torque study in the rabbit. Clin Implant Dent Relat Res 2005; 7:13-20.

73. Gahlert M, Gudeus T, Eichhorn S, Steinhauser E, Kniha $H$, Erhardt W. Biomechanical and histomorphometric comparison between zirconia implants with varying surface textures and a titanium implant in the maxilla of miniature pigs. Clin Oral Implants Res 2007;18:662-8.

74. Kohal RJ, Wolkewitz M, Hinze M, Han JS, Bachle M, Butz F. Biomechanical and histological behavior of zirconia implants: an experiment in the rat. Clin Oral Implants Res 2009;20:333-9.

75. Piconi C, Maccauro G. Zirconia as a ceramic biomaterial. Biomaterials 1999;20:1-25.

76. Gahlert M, Burtscher D, Grunert I, Kniha H, Steinhauser E. Failure analysis of fractured dental zirconia implants. Clin Oral Implants 2012;23:28793.
77. Andreiotelli M, Wenz HJ, Kohal RJ. Are ceramic implants a viable alternative to titanium implants? A systematic literature review. Clin Oral Implants Res 2009;20:32-47.

78. Kohal RJ, Att W, Bächle M, Butz F. Ceramic abutments and ceramic oral implants. An update. Periodontol 2000 2008;47:224-43.

79. Kohal RJ, Weng D,Bächle M, Strub JR. Loaded custom-made zirconia and titanium implants show similar osseointegration: an animal experiment. J Periodontol. 2004;75:1262-8.

80. Hoffmann O, Angelov N, Gallez F, Jung RE, Weber FE. The zirconia implant-bone interface: a preliminary histologic evaluation in rabbits. Int $\mathrm{J}$ Oral Maxillofac Implants 2008;23:691-5.

81. Caglar A, Bal BT, Karakoca S, Aydin C, Yilmaz H, Sarisoy S. Three-dimensional finite element analysis of titanium and yttrium-stabilized zirconium dioxide abutments and implants. Int J Oral Maxillofac Implants 2011;26:961-9.

82. Parel SM, Schow SR. Early clinical experience with a new one-piece implant system in single tooth sites.J Oral Maxillofac Surg 2005;63:2-10.

83. Kohal RJ, Klaus G, Strub JR. Zirconia-implantsupported all-ceramic crowns withstand long-term load: a pilot investigation Clin Oral Implants Res 2006;17:565-571.

84. Cionca N, Müller N, Mombelli A.Two piece zirconia implants supporting all-ceramic crowns: a prospective clinical study. Clinical Oral Implants Research 2015;26:413-8.

85. Nevins M, Camelo M, Nevins ML, Schupbach P, Kim DM. Pilot clinical and histologic evaluations of a two-piece zirconia implant. International Journal of Periodontics and Restorative Dentistry 2011;31:157-63.

86. Payer M, Heschl A, Koller M, Arnetzl G, Lorenzoni $M$, Jakse N. All-ceramic restoration of zirconia twopiece implants - a randomized controlled clinical trial. Clinical Oral Implants Research 2015;26:3716.

\section{Yazışma Adresi}

Merve Varol

Hacettepe Üniversitesi Diş Hekimliği Fakültesi Protetik Diş Tedavisi Anabilim Dalı/ANKARA

Tel: 0312-305 2240

Fax: 0312-311 3741 